\title{
CRAFT AS A FASHION ACTIVIST PRACTICE
}

\section{Stella Lange}

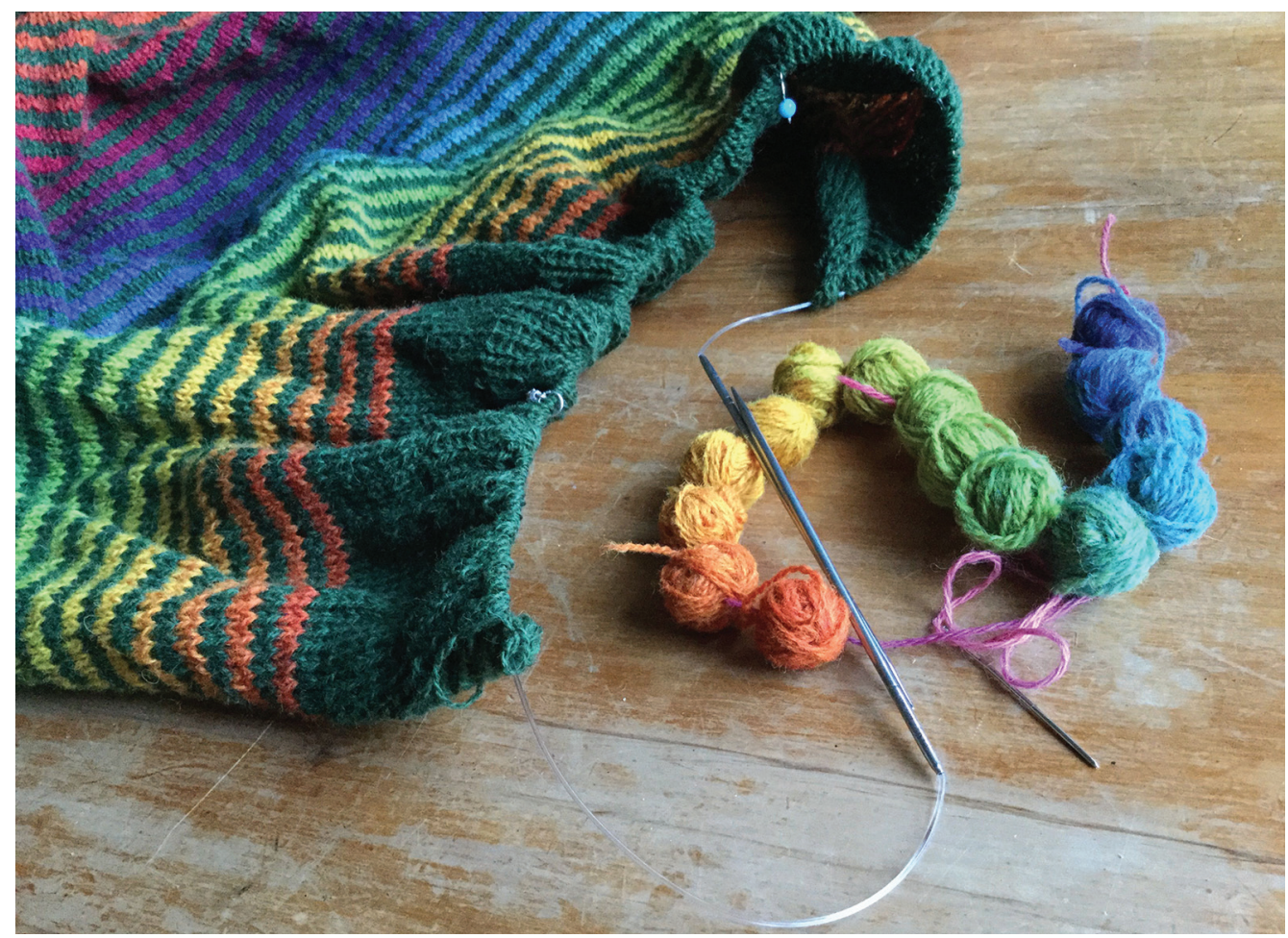

Figure I. Handknit in progress - customising colours to make a garment unique. Photo credit: Stella Lange, 2016.

Fashion is more than a commercial activity, more than a process of inspiration, design, production and distribution directed at consumers. Those called consumers have roles beyond consumption. Fashion is a dialogue between designers/producers and those who choose how to dress. Of the multiple viewpoints which can be used to examine "fashion practice," theories of "quiet activism" and craftivism have been little discussed. Fashion by its very nature illustrates and provides agency for wearers, a display of independent and free choice. Contemporary fashion is predicated on fashion designs being developed and then produced, marketed and distributed to the fashion public. The role of craft makers as fashion practitioners is little discussed beyond the role of the craft designer or craftsperson making for sale. One overlooked fashion practice is that of the craftsperson wearer. Positioning craft as part of a wearer's fashion practice, as craftivism, a deliberate activism, be it "loud" or "quiet," enables a consideration of alternative fashion practices. Those wearing fashion choose how they wear and maintain commercial fashion designs - and yet they are often categorised as mere consumers. My work has begun to tease 
out a form of fashion activism, undertaken by those who choose to work with fashion that sits outside of the design-production-distribution-consumption model. This is a practice of fashion where production is decentralised and more connected to the wearer and wearing. A fashion practice that signals a resistance to consumerism, in an authentic, and visible way - raising questions about how things are made and how we as people (not consumers) can create and maintain our fashion.

Fashion is defined by the Oxford English Dictionary as "a popular or the latest style of clothing, hair, decoration or behaviour," or alternatively as "a manner of doing something."The first definition seems far too narrow, too tight, too reliant on having just the right shoes or the right brand. The second definition - a manner of doing something - has more potential to describe the myriad of practices that constitute what fashion is. If fashion is a practice rather than specific items, a verb rather than a noun, then there is potential to discuss more nuanced kinds of fashion practice. When fashion is accepted as meaning more than having the 'right' bag, shoe or coat, then the potential to discuss practices that are used to create a fashionable identity is opened up beyond discussing the silhouette or colour of a particular item.

The traditional 'model' of fashion assumes that garments are designed and distributed within a system that is geared towards the commercial,' involving creation, production, promotion and selling. The thing 'sold' can be a garment, an image or aspirational fantasy. This model originated in the Industrial Revolution, when centralised production of textiles become the norm. Fashion became something offered to the buying public, something to be consumed. While this is still true for many fashion practices, there are legitimate fashion practices that lie outside or alongside these commercial systems.

Fashion, as a practice, provides agency, ownership of dressing and facilitates choices about the selection of garments, how they are worn and, beyond that, how things are maintained and cared for. Agency indicates an ability to act independently, to make choices without restriction. Fashion provides agency to both individuals and communities what is worn and how it is worn communicates a chosen identity. Amy Twigger Holroyd identified a type of fashion, "folk fashion," where wearers don't look to the high street for their wardrobe, but instead turn to craft in order to construct the kind of fashion they want to wear.?

As identified by Holroyd, folk fashion is a form that is not practiced professionally - rather, pieces are designed and made outside of the professional and industrialised system of fashion production and distribution. Craft occupies a significant space in Holroyd's folk fashion - knowledge and mastery of material selection, cutting, shaping, forming and finishing are all craft skills. Craftspeople differ from designers and artists in the fundamental principle that skilled individuals are at the heart of craft production. ${ }^{3}$ There is craft in conventional fashion - much fashion design utilises craft in the creation of new designs which are then outsourced for industrial production, while some niche products are designed and made by skilled craftspeople to be sold to a fashion public. The difference with folk fashion is that pieces are crafted by the 'folk' who wear them - not by industrial means or by craftspeople producing items for sale. Craft in this context refers to the practices used to make items individually, as opposed to the mass manufacturing processes employed to create huge numbers of identical products for commercial sale.

Craft has been discussed in various contexts - in terms of the mastery of form and process, ${ }^{4}$ its relationship to art, ${ }^{5}$ and in relation to history and theory. ${ }^{6}$ In my work, craft is seen as both a fashion practice and as activism. (A fuller discussion, debating nuanced definitions of craft, is thus outside the scope of this piece.)

Twigger Holroyd discusses the various reasons why wearers choose folk fashion. For some, it is about the act of making; for others, it reflects a desire to have something that fits their unique body or style; and for many it is a rejection of the limited offerings in style, colour and fit offered by the dominant fashion supply chains. When craft is used to create individual fashion, there is visible evidence that the crafter has autonomy over what they make and what they make visible to the world. Where these practices, fashion and craft, come together in craft fashion, each wearer displays their autonomy in their fashion choices. 


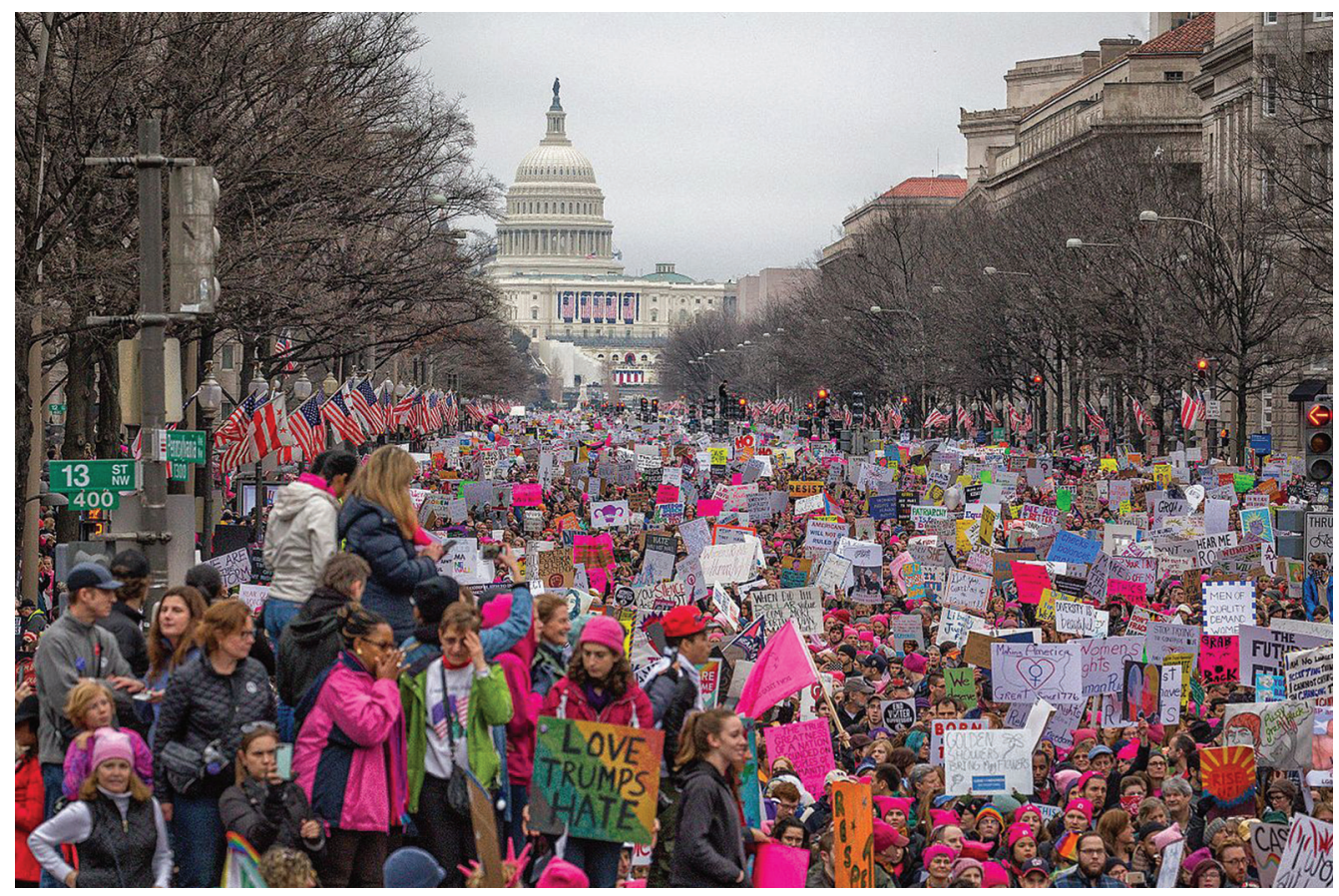

Figure 2. The Women's March on Washington (2I January 2017), discussed by Black (2017), an example of "loud activism," required the commitment to protest publicly, and required time, transport and a willingness to be identified in person and potentially in wider media coverage. Photo credit: Mobilus In Mobili - Women's March on Washington,

CC BY-SA 2.0, https://commons.wikimedia.org/w/index.php?curid=55796823.

Like fashion, activist practices undeniably provide agency to both individuals and communities. Activism is typically presented as visible protest. Activism seems most recognisable when it is loud, involving public demonstrations by individuals and communities in protest. However, activism, in many forms, can also be found operating at much quieter volumes, and these quieter voices deserve recognition as activist practices. Betsy Greer describes quiet activism and observes that "assertive" acts of activism are less attractive to many people.?

Shannon Black takes this a step further and discusses the gendered and social bias present in more visible and louder acts of activism. "Black theorises the "costs" of visibly "assertive" acts of activism, which she calls "loud activism" - for example, the Women's March on Washington held on 21 January 2017 (Figure 2). Taking part in visible displays of activism requires not only a desire to become involved, but also temporal, economic and societal considerations. For some, the time, cost and notoriety that accompany visible activism is beyond their personal agency.

Laura Pottinger discusses how activism is embedded in seed saving and sharing by gardeners, calling for "embodied activism at varying volumes" to be recognised, explaining that the power of these tiny and almost hidden acts of making and doing is that they "critique, subvert, and rework dominant modes of production and consumption."'10 Deliberate choices to construct and wear fashion that has not been mass-manufactured, distributed and sold to be consumed can be considered an activist practice.

To understand how craft fashion practices can be a form of activism requires understanding the theory behind "design activism." Design activism considers the way things are conceived, made and used. Alastair Fuad-Luke outlines three ways that activism is visible in design - anti-activism, slow activism and green activism." In anti-activism designers reject dominant or imposed practices, while slow activists seek to negate the expectations around rapid 
change that accompany contemporary life. Green activists prioritise ecological choices. Each of these pathways describes a way to understand and analyse activist practices - but, importantly, they can also be used to identify and describe quiet activist craft fashion practices.

When used as a fashion practice, as an activist practice, craft allows for a gentle engagement that is no less authentic than the more visible and louder activist approach. Unlike these more visible forms of social activism, craft, in the form of quiet activism, has the potential to resonate with a wider range of people than noisier disruptive action.

Craft fits comfortably alongside theories of leisure and fashion. Acts of craft and acts of fashion both require what are often considered luxuries - of time, space, and materials or money. Craft, and fashion, seen as a leisure activity, is something done to 'relax' and is very much considered part of the practitioner's identity.

Like fashion practitioners, many craft practitioners have a growing awareness of how their practices can be positioned as a response to consumerism. This is driven in part by increased awareness among consumers of the environmental and social damage of the increased consumption of what are called consumer goods, material possessions. Fast fashion has been identified as one site of visible over-consumption; ${ }^{12}$ what is unclear is the extent to which fashion consumers can recognise the difference between fast fashion and post-industrial commercial fashion production in general. While academics discuss and debate alternatives to fast fashion, ${ }^{13}$ how widespread this distinction is among ordinary fashion practitioners is not known.

It is important to recognise craft as an activist act and at times as an activist fashion act. By its very nature craft activism, like design activism and fashion activism, contests the conventions that determine how things are made. Craft fashion throws the spotlight on working conditions and highlights the disruption between the mechanised and the humanised worlds of production (Figure I). Craft hints at a viable alternative to global supply chains. Craft positions some of its labour in a domestic space and in so doing cast a shadow over the way that industrial products are made. Lisa Lou has articulated this point: "The story and the way things are made is very important, it is part of the meaning ... I don't think you can separate the meaning from how things are made. ... if we do that, then what we do is negate labor, and the people that are part of a process."'14

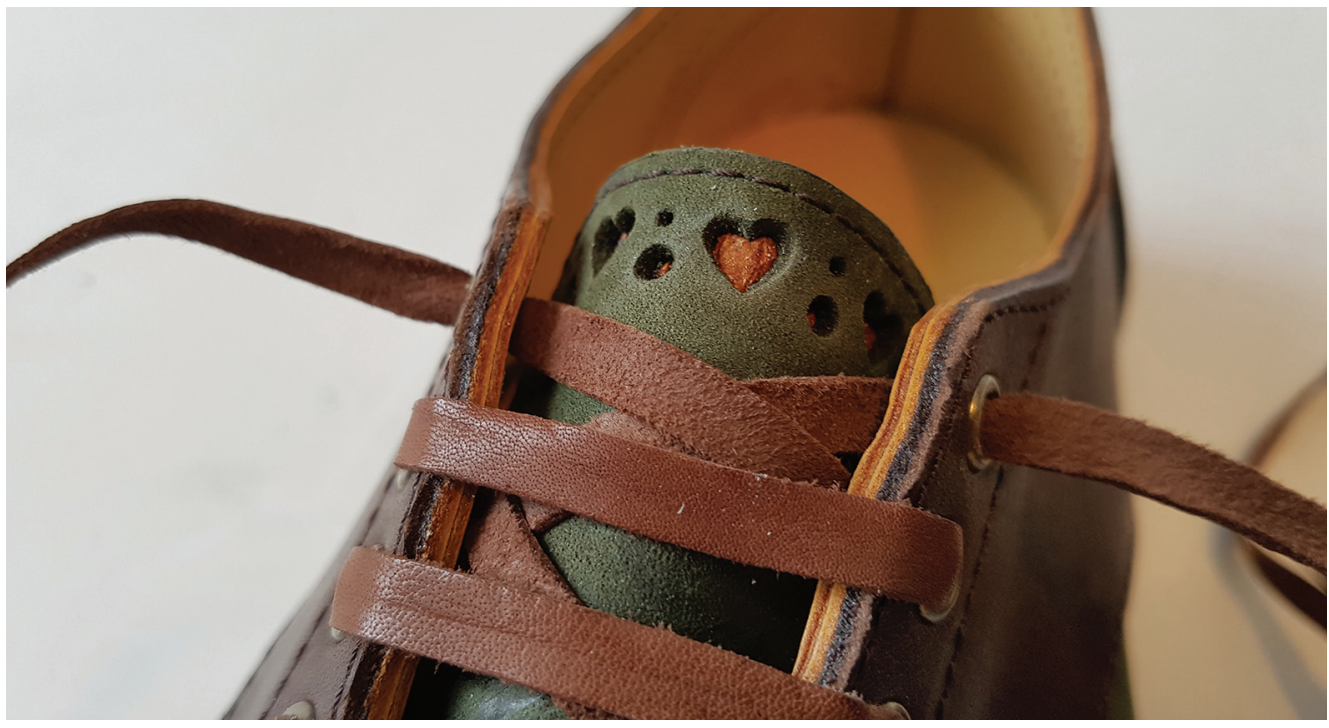

Figure 3. Hand-crafted shoe. I crafted this as a participant at Shoe School (http://www.shoe-school.com),

a workshop for handmaking shoes. Participants are guided through the process of designing and crafting a pair of handmade shoes - a very deliberate commitment of time and money. Photo credit: Stella Lange, August 2016. 
Craft fashion can be positioned in the space that Fuad-Luke calls "half-way products," items partially made and intended to be finished by the consumer. In disrupting the conventional manufacture process where objects are provided to consumers in a competed state, craft materials can clearly become activist products. This finishing by the consumer, the crafter of the intentionally half-made product, allows the labour to be partly supplied by the consumer - and in this way all craft can be positioned as an activist practice. ${ }^{15}$

Beyond simple labour, craftivism also signals a resistance to how things are made and, beyond this, how things are maintained. Bratich and Brush explain that watching someone knit garments, fashion garments, reveals alternatives to mass production. ${ }^{16}$ Garber describes craft as "a human microphone of makers and viewers." ${ }^{17}$ The simple act of crafting - by its very difference from the alternatives - is a deliberate choice (Figure 3). If the craft itself is the microphone, then the article works as the sound - amplified by the act of being made outside of a factory. The internet provides examples of crafted fashion as an alternative to mass-produced offerings, and the potential to be an example itself.

Activist practice focuses on the way that the craft space presents an alternative to the factory sweatshop for producing domestic textiles. Black cautions against the blank acceptance of craft being used in activist efforts ${ }^{18}$ - and this is right, but there is always a sub-element in craft where someone is rejecting a dominant consumer approach to life. Fuad-Luke ${ }^{19}$ describes activism as "thinking, imagination, and practice applied knowingly or unknowingly to create a counter-narrative aimed at generating and balancing positive social, institutional, environmental and/or economic change."

Fuad-Luke discusses the role of the artefact in activism, highlighting how "demonstration artefacts" reveal alternatives. Craft or folk fashion provides evidence that mass-manufactured and commercial fashion is not the only option. As a time-consuming act, crafting highlights the deliberation, the planned decision to create or modify fashion artefacts instead of purchasing readymade.

Importantly, according to Fuad-Luke, activism can be an unconscious act; individuals may feel a need, or a sense of unease to which they are responding, without being able to fully and clearly articulate their reasons and underlying concerns. Even when fashion crafters do not recognise or name their crafted work as activism - by its very rejection of a dominant mass-production mode - craft fashion is still activism.

Industrialised and globalised production of much of the 'stuff' we use, and the branding myths associated with it, are often at odds with individual experiences and ideas. In New Zealand we are told that our merino comes from our beautiful high country, yet we find labels indicating that the garments were not produced here. New products are marketed as slow fashion - thus solving the problem of rampant consumerism - and yet require us to purchase and consume them. According to Fletcher and Grose, up to 80 percent of the environmental cost of a garment occurs during the ownership period, not during production, so careful shopping alone won't provide the solution. ${ }^{20}$ As consumers, we are urged to be conscious shoppers, to be informed about our choices. Retail activism is distinctly at odds with anti-consumerism, and so creates a dilemma. How can individuals align with anti-consumerism and yet own industrialised and mass-produced products?

Craftivism answers the question, what does anti-consumerism look like?

In the Western world, consumerism is a dominant theme of the twentieth and twenty-first centuries. Many historians trace this back to Bernard London's influential 1932 essay which sought to resolve the economic slump of the 1930s. ${ }^{21}$ While many other factors have contributed to the growth of widespread consumerism, London's concept of planned obsolescence influenced developments in industrial production and product life. The central idea of London's plan was to stop making items that were durable, and instead design and produce items that had a limited life. This approach was key to long-term employment in both retail and industry. We no longer live and dress in a world where buying fashion products provides much-needed employment - instead, we are now facing the consequences of overproduction, and buying less is the new goal - an approach promoted as part of slower fashion. ${ }^{22}$ 


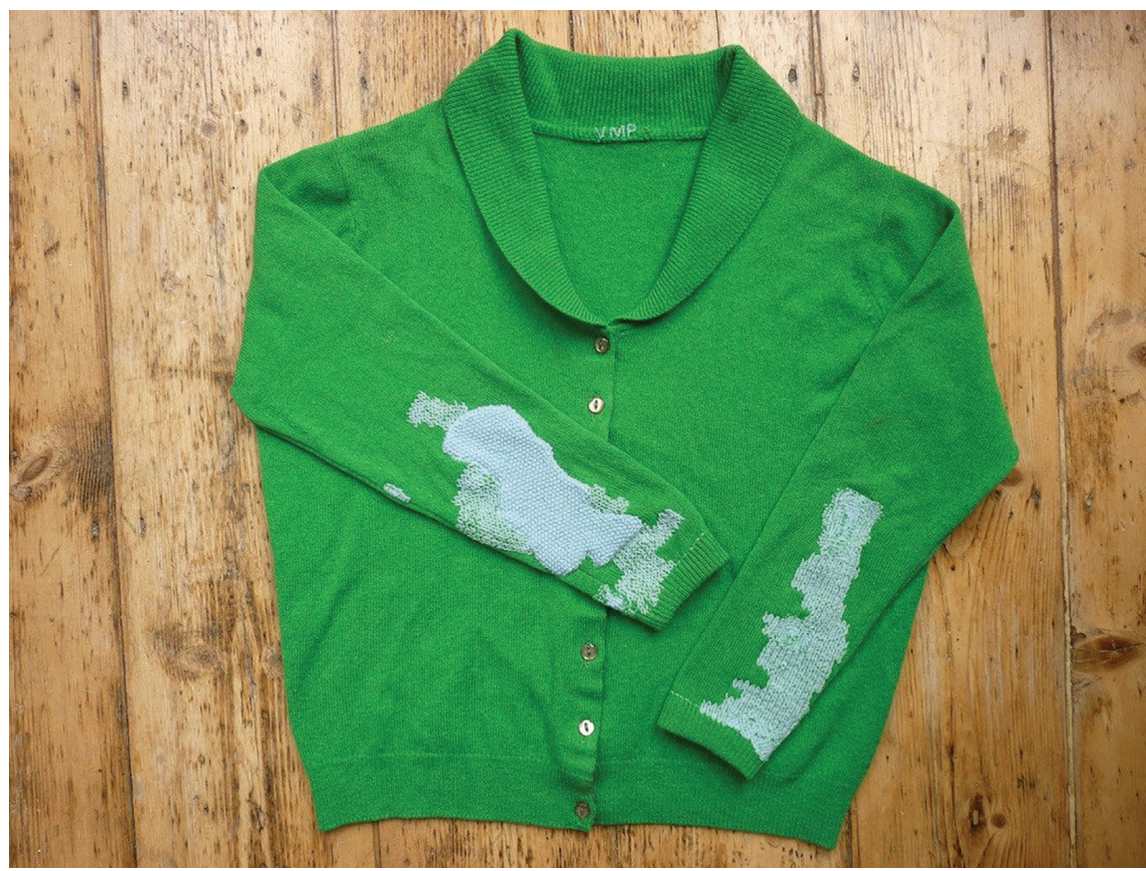

Figure 4. "The Visible Mending Programme \# I I,THAT Green Cardigan,"

27 January 2012,TOMOFHOLLAND, https://tomofholland.com/20 I2/0 I/27/the-visible-mending-programmeI I-that-green-cardigan/ (before and after). Reproduced with permission from https://tomofholland.com.

Perhaps the term 'consumer' itself needs to be questioned - consuming implies acts of using, of finishing and, implicitly, of needing replacements. Many forms of design activism reject the idea that people are consumers; instead, the goal becomes not to consume, but to reduce the act of consumption. This style of activism takes many forms - Reduce, Reuse, Recycle, Repurpose and, what is often the missing R - Repair. Crafting and craftivism offer partial solutions that fit with contemporary lifestyles.

Garber points out that for many in craftivism, the act itself is more important than the thing being produced. ${ }^{23}$ Repair can be seen as both a personal act of activism and as a more publicly recognisable act of anti-consumerism. Repairs say clearly: "I didn't go shopping" and "This is my slow fashion."

Buying second-hand is also an alternative to consumerism - but can be far less visible. Where fashion is curated in consignment shops - specialist boutiques which broker the selling of privately owned fashion garments - there is nothing to communicate that the item was not bought new. Because older or vintage second-hand garments can look different to current fashion offerings (in style or fabrication), wearing such garments can be examples of activism. Mending and repair - both in the act of practice and in the act of display - are more likely to communicate activist choices and values to others.

In our incredibly connected world, and via the social media mechanisms that allow individuals to find and connect to others with whom they share ideas, in presenting their acts of repair and of crafting, individuals - beyond being actors - can provide tangible, visible evidence that they 'did something.' In his Visible Mending Program (VMP), Tom of Holland does just that. Tom van Deijnen (his real name) is an influential textile repairer, regularly interviewed in the Guardian and invited by Burberry and Selfridges to work with their brands to highlight the craft of repairing. Tom's online presence highlights both making and mending - his VMP project showcases a craftivist approach to owning garments. (Figure 4). 
Mending and its twin, repair, has a long social history. The meaning of repair has shifted significantly over the later twentieth century. As crafivist acts, repair and mending have shifted from the secret and private domestic sphere into a more visible, public space. Even when an item is one that would not usually be visible when worn - like the socks in Figure 5 - the evidence of acts of repair can be very public.

In addition, details of how the repair was made are often spelled out, as in the blog post series by Hunter of Pantsville Press about "that cardigan." 24 Figure 8 represents one of thousands of images online which present what appears to be a how-tomend tutorial, but which can also be read as a demonstration, a permanent and public capture of an act of quiet, authentic craftivism, of repair.

These acts are authentic as they result in change but, unlike other activists strategies like protests, they do not demand that others change what they do. The Pantsville Press blog also presents other visible acts of repair, where garments are stitched and either the process or the result is presented publicly (Figure 6). In New Zealand, at Sew Love, Sarah Lancaster and her a vintage camper van, Cecil, kitted out with solar-powered sewing machines, tours the country offering equipment, lessons and clothing repairs on the spot (Figure 7). For Sarah, "teaching people how to mend their own clothes is a form of empowerment for the consumer, rather than buying more."

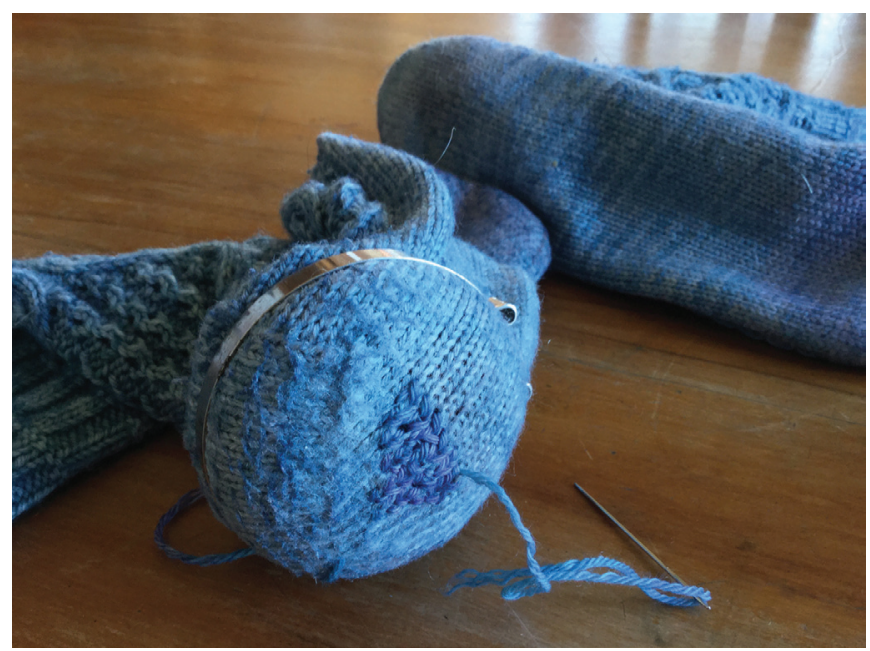

Figure 5. The author's visible mending in action. Photo credit: Stella Lange.

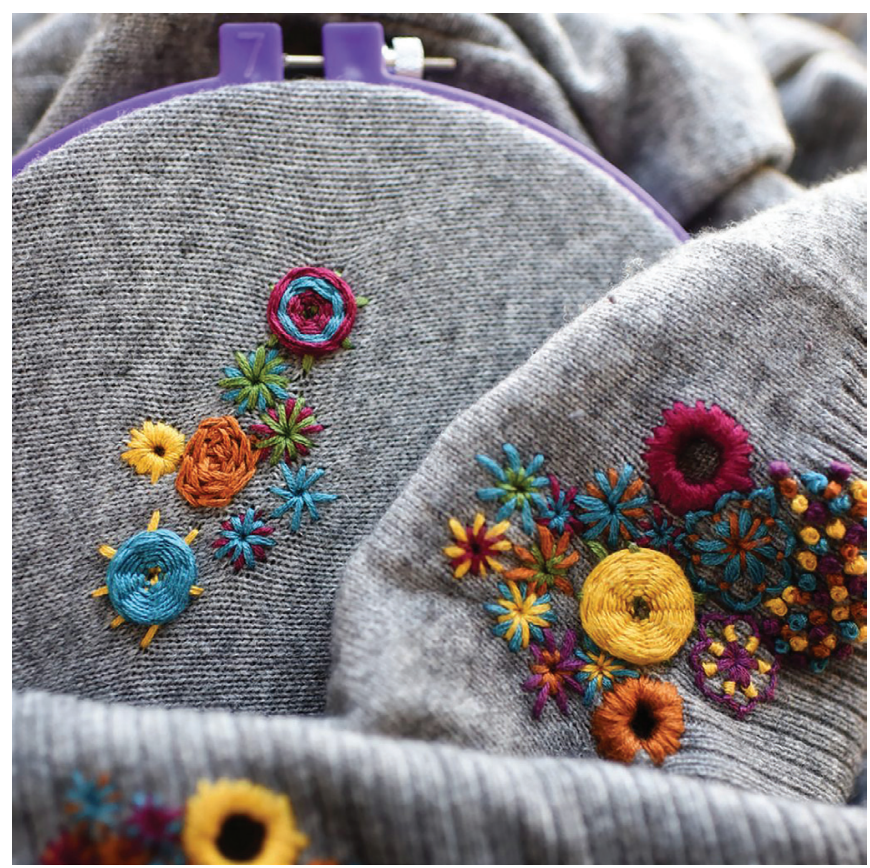

Figure 6. One example from Pantsville Press of a visible act of mending, a decorative and communicated act of craftivism.

Reproduced with permission from https://pantsvillepress.com (retrieved 12 August 2019) 


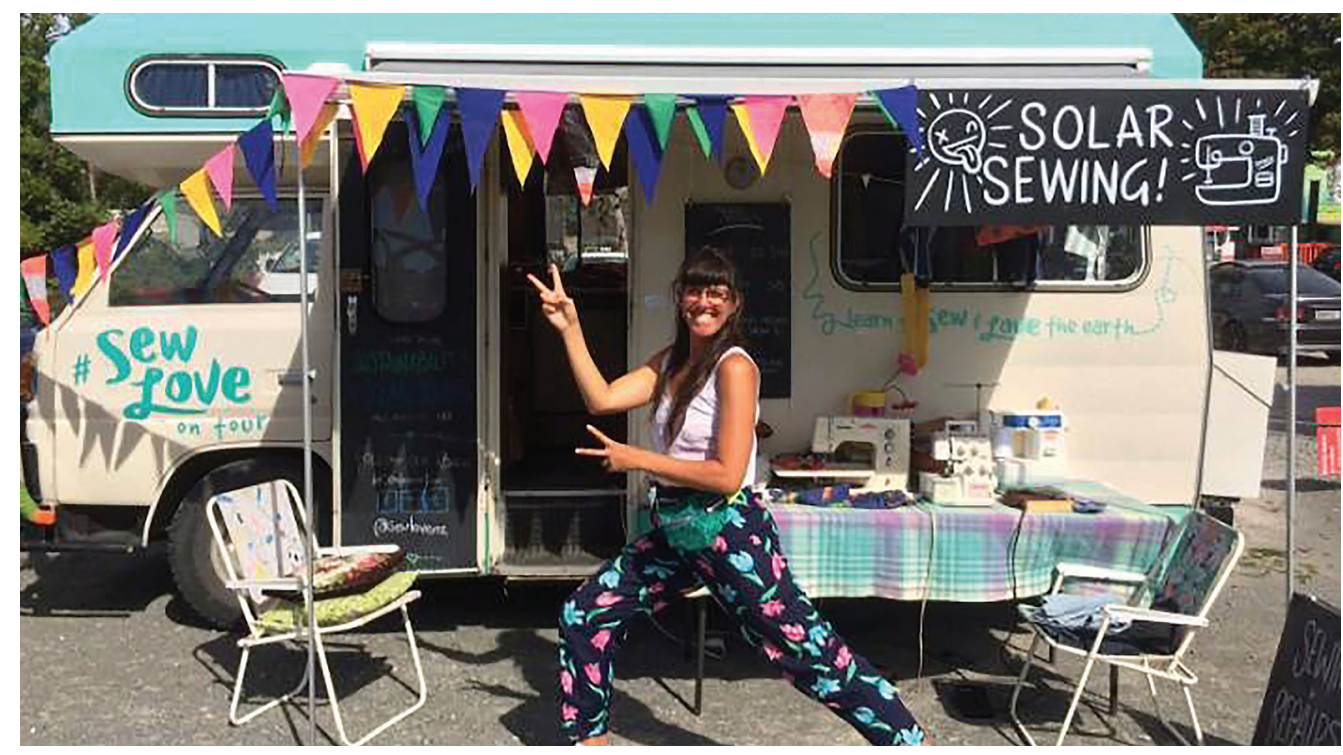

Figure 7. Sarah Lancaster actively promotes and educates others in repair and making to empower consumers around New Zealand using Cecil, her solar-powered mobile home fitted out with multiple sewing machines.

Reproduced with permission from image owner (retrieved 12 August 2019).

Locally, in Dunedin, New Zealand, Fiona Clements, of Señorita AweSUMO, runs make-and-mend sessions every month from her workshop, Just Atelier. These practioners are not alone - many others promote and showcase craft-based approaches to modifying fashion, as demonstrated in person and online.

Within craft there are hierarchies, separations by skill, by material, by approach. Some repairs are informed by the repair practices of others, and draw on history. Mending work in the style of boro and kintsugi are sympathetic to a quiet activist approach in that they are highly decorative. Boro is a form of visible repair once employed in Japan by the very poor - it is often grouped with sashiko. Both are a type of embroidery that uses running stitches and are now popular as a decorative method of stitching and mending. Katrina Rodabaugh's Mending Matters is one of many books, print and online articles that provide "a slow fashion guide for a well-loved wardrobe."'25 In these publications, the primary focus is on the act - the act of repair overshadows any story about the garment or other benefits of mending. The garment becomes a site of activism, of craftivism, of quiet craftivism.

These examples are not isolated, but are drawn from a wider pool of authentic craft activism, of visible activism - craftivist actions recorded online that provide evidence of a rejection of consumerism. Contemporary repair practices signal a resistance to consumerism in an authentic and visible way - raising questions about how things are made, and how we as people (not consumers) can create and maintain our fashion.

Stella Lange (10000-0002-3676-433I) is a Principal Lecturer at the School of Design, Otago Polytechnic, working with undergraduate and post graduate students. Stella'a research looks at the care and repair of domestic textiles, and social expectations of textile repair in 20th Century New Zealand. Her practice is primarily textile based, primarily hand knitting, extending to spinning, stitching and weaving but includes drawing and writing. 
I Nicola White and lan Griffiths, eds, The Fashion Business: Theory, Practice, Image (Oxford: Berg, 2000).

2 Amy Twigger Holroyd, Folk Fashion: Understanding Homemade Clothes (London and New York: IB Tauris, 20 I 7).

3 Colin Gale and Jasbir Kaur, “The Craftsperson," in their The Textile Book (Oxford: Berg, 2002), 63-75.

4 David Pye, The Nature and Art of Workmanship (London:The Herbert Press, 1968).

5 Peter Dormer, The Culture of Craft (Manchester: Manchester University Press, 1997).

6 Richard Sennett, The Craftsman (New Haven, CT:Yale University Press, 2008); Howard Risatti, A Theory of Craft: Function and Aesthetic Expression (Chapel Hill, NC: University of North Carolina Press, 2007).

7 Betsy Greer, Craftivism: The Art of Craft and Activism (Vancouver, BC: Arsenal Pulp Press, 20I4).

8 Shannon Black, "KNIT + RESIST: Placing the Pussyhat Project in the Context of Craft Activism," Gender, Place \& Culture, 24:5 (2017), 696-710, https://doi.org/l0.1080/0966369X.2017.1335292.

9 Laura Pottinger, "Planting the Seeds of a Quiet Activism," Area, 49:2 (20 I7), 215-22, https://doi.org/ I0.1 I I I/area. I 23 I 8.

10 Ibid., 215.

I I Alastair Fuad-Luke, "Key Design Movements," in his Design Activism: Beautiful Strangeness for a Sustainable World (New York: Earthscan for Routledge, 2009), 203-13.

I2 Kate Fletcher and Lynda Grose, Fashion and Sustainability: Design for Change (London: Laurence King Publishing, 20 I2); Alison Gwilt and Timo Rissanen, eds., Shaping Sustainable Fashion: Changing the Way We Make and Use Clothes (London: Routledge, 20 I I), http://www.amazon.com/dp/I 84971 24I7; Safia Minney, Slow Fashion:Aesthetics Meets Ethics (Oxford: New Internationalist, 2016).

13 Kate Fletcher, "Slow Fashion: An Invitation for Systems Change," Fashion Practice, 2:2 (20 I0), 259-65, https://doi.org/ I0.2752/I 756938 I OXI 2774625387594.

14 Liza Lou, cited in Jessica Hemmings, "Liza Lou: Shifts in Aspiration,” Surface Design (spring 2017), 32-7.

15 Ibid.

I6 Jack Z Bratich and Heidi M Brush, "Fabricating Activism: Craft-work, Popular Culture, Gender," Utopian Studies, 22:2 (201 I), 233-60; Hemmings, "Liza Lou."

17 E Garber, "Craft as Activism," The Journal of Social Theory in Art Education, 33 (2013), 53-66.

18 Black, "KNIT + RESIST."

19 Fuad-Luke, "Key Design Movements."

20 Fletcher and Grose, Fashion and Sustainability.

21 Bernard London, Ending the Depression through Planned Obsolescence, 1932, http://upload.wikimedia.org/wikipedia/ commons/2/27/London_\%281932\%29_Ending_the_depression_through_planned_obsolescence.pdf.

22 Michael Clarke, "Exhibition Review - Madeleine Vionnet: I 5 Dresses from the Collection of Martin Kamer," Fashion Theory, the Journal of Dress, Body, and Culture, 6:3 (2002), 323-6; Fletcher, "Slow Fashion."

23 Garber, "Craft as Acivism."

24 "Done! Er...for Now... | Pantsville Press," https://pantsvillepress.com/2018/I0/I8/done-er-for-now/ (accessed I3 August 2019).

25 Katrina Rodabaugh, Mending Matters: Stitch, Patch, and Repair Your Favorite Denim \& More (New York: Harry N. Abrams, 20 8 8). 